\title{
Informal Practices, Formal Regulations. Understanding Informality as Spatial Dialectics
}

\author{
Andrea Varriale ${ }^{1, a}$ \\ ${ }^{1}$ Belvedererallee 5, Weimar, Germany \\ aandrea.varriale@uni-weimar.de
}

Keywords: Informality, Spatial Dialectics.

\begin{abstract}
The concept of urban informality, mostly referring to housing or economic activities, is usually used in two different fashions. Some liberal scholars see informality as a primordial forms of entrepreneurialism or as "deep democracy" which is made possible by the ineffectiveness of state's attempts to regulate the relevant matters. They typically call for a the legalization of informal practices and their integration in state structures. A more critical perspective sees informality as emanating directly from state's power to define the boundaries of "formality" and to arbitrarily deprive some of its citizens from their rights. The distance between these two interpretations leaves a gap which offers little theoretical foundations for analyses of phenomena of spatial informality which can be understood neither as entirely unrelated to the state, nor as being determined by it. The paper seeks to fill this gap by proposing a third view of informality, which is built upon Lefebvre's model of "spatial dialectics".
\end{abstract}

\section{Introduction}

It is difficult to locate the birth of the concept of informality and to follow its evolution in scientific literature. One source of this difficulty relates to the fact that much relevant thinking has been produced by scholars working in disciplines only marginally concerned with urban questions. This is, after all, the big question of how power works. Yet, this paper seeks to organize some relevant literature dealing with "urban informality" and to show the pros and cons of its two main approaches.

In order to reduce the risk of wandering helplessly in the growing literature on the topic, this paper focuses on the more narrow concept of "urban informality". A limit of this rough selection is that it privileges those works which deal with "urban informality" under that precise name, whereas other relevant work is pushed to the background. In the final remarks, however, the paper offers some considerations on the conceptualisations of informality in general, insofar as they are relevant to how urban informality has come to be understood. The paper consists of two parts. Firstly I schematise the most important literature on urban informality by using a scheme which divides it into two opposed perspectives. These are named here "liberal" and "critical", respectively. Needless to say, both the distinction and the labels are an interpretation of the author. They do little justice to the richness of each approach, and it downplays the intellectual honesty of many authors who recognize their own limitations and have proposed ways to elaborate on them. Yet, this distinction seems worth keeping insofar as it allows to clearly locate a gap in the theorization of urban informality. This gap consists in the lack of a concept of urban informality which could accommodate examples of informal usages of space which are neither unrelated to the working of the state (as in the liberal perspective) nor essentially determined by it (as in the critical perspective). In its final part, this paper proposes a middle-of-the-road conceptualisation of urban informality based on "spatial dialectics", a conceptual model elaborated by Henri Lefebvre.

\section{The liberal perspective: Informality as pre-modernity.}

The overwhelming majority of studies on urban informality deal with phenomena taking place in the "global south". This should come as no surprise, since much impulse in this direction has come from the field of "development studies" and its core quest to understand the effects and the causes of "underdevelopment" in what used to be called the Third World. Much of such analyses implicitly 
took for granted the cornerstone of "western states", which were uncritically assumed as basis for comparison. The work of Keith Hart on informal economic activities in urban Ghana [1] is among the most widely cited examples of this approach. He noticed how, "[having been] denied success by the formal opportunity structure, these members of the urban sub-proletariat seek informal means of increasing their incomes" (p.67). The "urban informals" were thus a heterogeneous group of (officially unemployed) self-employed people, as opposed to "formal" wage-earners and employees. Hart anticipated thus a major theme in the scholarly debate on informality, namely the question whether people who are engaged in informal practices should be understood as "exploited, passive" individuals who have been brushed aside by the "formal economy", or whether they hold a degree of autonomy in their attempts to work out unorthodox, informal strategies in a context of economic deprivation. He supported the latter view. Hart's dualistic view of the informal economy would soon be adopted by the International Labour Organisation and other institutions such as the United Nations and the World Bank. It has been argued that the success of this dualistic interpretation is connected to its mild policy implications, which suggest the possibility of helping out the "informals" without any radical questioning on the role of the state. Among the most significant limits of the liberal view is its implicit assumptions that formal employment always offers stable incomes and economic security, which is yet another consequence of the uncritical transposition of Western ideas in radically different contexts [2]. Other major points of criticism will be outlined in the next chapter.

Research on the informal economy received new impetus after the end of the Cold war, with the general "retreat of the state" from the economy throughout the world. It is in this context that Hernando de Soto [3] proposed his interpretation of informal economic activities as strategies adopted by individuals whose entrepreneurial spirit would otherwise be limited and frustrated by the strictures of formalised labour. According to this view, sometimes referred to as "legalist", the fates of informal labourers would be improved if their activities and assets were formalised and thus integrated in the formal property market. In a similar vein, other authors see the work of civic committees and NGOs as valid alternatives to state-sponsored social services, and look at the former as carriers of "deep democracy" [4]. A similar anti-statist thinking can be discerned in how the United Nations have come to understand informal housing. The UN Habitat II Agenda (1996) introduced a new strategy for the provision of housing for the poor, which revolved around the idea of states "enabling" communities to provide for themselves, rather than stepping in directly. Thus, the scope of central governments was seen as limited to the provision of affordable land and the protection of private property (for a sympathetic account, see [5]).

For clarity of exposition, some limits of this approach may be already anticipated. In general terms, this approach seems misleading for it presents informality as a context where the agency of "informal actors" (mostly, the poor) is augmented by the absence of the state. Similarly, it tends to overrate the climate of equal opportunity which would prevail among people who dwell and work outside of state's reach.

\section{The critical perspective: Informality as exclusion}

At least since the 1970s, a critical branch of works has emerged in contrast to what were seen as the shortcomings of the liberal approach. The main line of reasoning was inspired by the "dependence theory" elaborated by Marxist international economists. Just as Gunder Frank famously argued that "underdevelopment is developed", critical urban scholars argued that the so-called "marginalised" population is not, in fact, marginal at all. Rather, the exclusion of certain categories of people from basic services and from the fruition of civic rights is functional to the preservation of the well-being of the better-off strata of the society. As Janine Perlman argued, the very concept of marginality is a political mystification, a discursive manipulation which justifies and reinforces the discrimination and the exclusion of the urban poor by the elites [6]. This is the line of argument adopted by authors such as Ananya Roy and Nezar AlSayyad [7] in their important contribution to the debate on urban informality. Some chapters of their book offer very clear examples of this conceptualisation. In their study of informal settlements in Israel/Palestine, Oren Yiftachel and Haim Yakobi [8] present their tripartite model of how the condition of informality, and the lack of citizenship rights connected to it, 
result from the combined action of the "logic of capital", bureaucratic governance and the drive for ethnic control of the state.

\section{A critical appraisal}

As was anticipated above, this paper argues that each approach has its limitations. This paragraph delves deeper into such limitations and highlights few critical nodes around which the gap between the two perspectives is the widest.

One point revolves around the question whether informality is an intentional outcome of the state action. This is perhaps where the two approaches diverge the most. De Soto argued that informal practices are a sub-optimal, yet necessary, "safety valves" which poor people use in order to escape the constraints that the state places upon them. In this respect, we might say that the liberal approach tends to see the state's attempts to regulate and control informality as both hopeless and counter-productive. What states are asked to do is merely to "convert" the poor's informal assets (e.g. the land they "illegally" occupy or their unlicensed economic activities) into formal ones. The recognition of their assets would thus allow formerly (and formally) poor people to access the property market and thus give greater scope to their entrepreneurialism. Critical scholars argue instead that the state is itself responsible for the existence of "spaces of informality". Suffice it to recall here Perlman's statement that "marginality" is the product of marginalising policies or Yiftachel's study on how states intentionally deprive some people of their citizenship rights. Thus far, it seems that the question whether the state is responsible for the presence of spaces of informality cannot be answered directly. But this is so because another aspect of the discussion has remained so far unmentioned, and namely the question of what exactly "states" are able to do. Once again, the two approaches differ widely. If authors in the liberal tradition tend to interpret state's failure to regulate some areas of economic life as an intrinsic limitation of "big governments", critical theorists are less inclined to see such failures as a "unintended consequences" but rather see them as a deliberate strategies of control. Once we have added the dimension of power (or effectiveness of governments), we can at least argue that a state should be held responsible for "creating" spaces of informality only as long as it would be in its power to undo them. A more sweeping criticism can be levelled against this point of the debate, and namely that both the powerfulness and the intentionality of the state are, and should remain, questions whose answers should be found empirically, and not in a-priori, theoretical debates. This is of course to imply that, generally speaking, states differ among themselves not only in their intention to regulate certain areas of social life, but also in their actual ability to do so.

A second critical point concerns the very different epistemologies adopted by the two approaches. Authors in the liberal approach typically adopt an actor-based paradigm, or, to put it differently, they presuppose a world in which rational individuals make their choices in order to improve their conditions. Critical urban scholars, instead, more typically adopt a structuralist paradigm, whereby actors' conditions and strategies are greatly constrained (if not outright determined) by their economic and social position. To be fair, there exist different nuances within the critical perspective. Among other things, this can be seen in the wealth of writings on urban informality which seek to document the tactics used by the under-privileged classes to contest or change their conditions (for an outstanding example, see [9]). However, I would argue that epistemological individualism cannot be integrated within a structuralist/Marxist framework, and that a clear and consistent choice must be made. While an individualist epistemology "zooms in" into the interpretations and the strategies of individuals, a structuralist approach more often "zooms out" onto strategies of larger groups of people (or classes), thus highlighting the structural constraints which affect their collective action. Perhaps unsurprisingly, I would again argue that the extent to which actors are limited by structural constraints (e.g. by extreme poverty or by their exclusion from legal protection) should only be answered on the basis of empirical data and not be derived by any theoretical consideration.

The third limit of the discussion on informality is its rare realization that both formality and informality are modes of action, or sorts of "habitus" (in Bourdieu's sense) that individuals use in order to achieve specific goals. Formality and informality should not, in other words, be used to describe certain social groups, even less certain "deprived" areas. With this regard, it is striking how 
the majority of studies on urban informality implicitly assumes that informal uses of space are mostly associated with the poor (for a notable exception, see [10]) and with developing countries. Understanding informality as practice instead would allow researchers to point out more easily how informal practices are also used by the well-off, both in poor and in rich countries. It should be noted such an understanding points to a people-centred study of place. In this kind of study, a place (e.g. a neighbourhood of a city) would not simply be labelled as "formal" or "informal", but it would rather emerge as the stage where formal and informal practices interact [11]. This emerging approach comes close to Lefebvre's theory of the "social production of space" [12]. The latter will be sketched out later as a possible synthesis between the two conceptualizations of informality so far outlined.

Last, but not least, a very slippery discussion point revolves around the question of whether formality or informality are, per se, desirable conditions. This is, in other words, the question of normativity. Generally speaking, authors within the liberal approach are optimistic about the opportunities which people are afforded in regimes of informality. An illustration of that are De Soto's success stories of poor farmers and labourers who, thanks to a benevolent and farsighted government, manage to get their informal property recognised. This recognition is what, in the eyes of De Soto, will allow formerly poor people to capitalise on their assets while benefitting from the legal protection of the state. The condition of informality is thus seen as a primitive but essentially innocuous stage for the further improvement of entrepreneurial citizens. It is not as easy to conclude what is the prevailing normative view among the critical scholars. On the one hand, state structures are keenly denounced as legal fictions which freeze and legitimise inequalities (e.g. when informal dwellers are evicted after their homes have been declared illegal). Yet, the very fact that people's exclusion from the legal system is denounced for its negative consequences reveals an implicit assumption that the very state which is seen as excluding its citizens is the potential future provider of citizens' rights. It is important to take this dissonance seriously, for this is another reminder that the categories of formality and informality refer essentially to modes of actions, to ways of doing things, rather than to specific kinds of actions. Out of metaphor, a state exercises formality both when it evicts informal dwellers and when it provides social housing. Which of the two is preferable has nothing to do with formality and informality, but should be derived from an explicit political stance. Similarly, street vending may be illegal in a given country and allowed in another. The "informal" vendors will probably have to learn the trajectories of police patrols but will pay no (official) taxes, while "formal" vendors will probably be more preoccupied with maintaining their licenses and not be indicted for tax fraud. Once again, which of the two is the more desirable option depends very much on the specific ways the actual action takes place, rather than on whether that activity is carried out in a formal or informal fashion.

\section{A possible synthesis? Informality as dialectics}

This paragraph attempts to collect and integrate the critical points highlighted above and proposes an alternative concept of urban informality. Ideally, such a notion of urban informality should: (i) leave open the question whether the state is unwilling or unable to "formalise" the field of social interaction considered; (ii) be consistent in its epistemology, e.g. by adopting an actor-oriented paradigm if it seeks (iii) to recognise on actors' uses of formal and informal modes of action; lastly, it should (iv) leave open the question of whether a formalisation of informal practice would be a desirable or undesirable outcome for the relevant actors.

One way of crafting such a conceptualisation of urban informality is to integrate the abovementioned analysis of informal practices with Lefebvre's theory of "the production of space". This theory is based on a threefold model which highlights the interplay of political and social aspects in the usage of space [13], which he termed "spatial dialectics". The first element of his model are Spatial practices, or the physical space when used in routinized and non-reflective fashions. Representations of space, instead, designate the spatial order as it is conceived by planners and social engineers, an order which is enforced by the state. The last element are Spaces of representation, or space as reflexively lived by users who, while being aware of the political significance of spatial order introduced by the state, consciously contest it and seek to implement new ways of using that 
space [13,14]. Therefore, Representations of space can be taken as conceptualising spatial policies or formality, whereas Spaces of representations conceptualise the informal and critical reactions they provoke.

In guise of a conclusion, let us see how this model can respond to the questions left open in the previous chapter. Firstly, Lefebvre's model is open-ended, that is, it says nothing on how the interaction (or clash) between the State and critical citizens will ultimately end. This caution seems very useful, since it forces the researcher to turn to the empirical reality in order to know whether, in a given space, a state's attempts to regulate its usage have been carried out and, if so, whether these attempts have been successful or not. Secondly, Lefebvre's model is explicitly designed in opposition to structuralist conceptualisations of space, that is, against the idea that space be totally dominated by the hegemonic power of elites. He wrote: "Some over-systematic thinkers oscillate between loud denunciations of capitalism and bourgeoisie and fascination and admiration on the other. They make society into an 'object'. [...] They thus bestow a cohesiveness it utterly lacks upon a totality which is, in fact, decidedly open. So open, indeed, that it must rely on violence to endure" (1 p. 11).

Precisely for this reason, his "spatial dialectics" seems appropriate for a study of urban informality which wishes to recognise, also on the epistemological level, actors' ability to act within and beyond existing economic, social and legal structures (their agency, in other words). This can account for the point (ii) of the previous chapter, namely the need to carefully match the intended object of study with a fitting epistemology.

Yet Lefebvre's model can only take us thus far, and a study of urban informality (at least as has been outlined here), would need to depart from it in two significant respects. On the point (iii), I argued that formality and informality, rather than representing two different kinds of actors (or two different kinds of places) can be best understood as representing two different modes of actions. The underlying idea is that actors (be them government officials or urban activists) may in fact behave both formally and informally, the choice depending on the specific situation at hand. Lefebvre's model does not quite point in that direction, at least not directly. For him, the production of space, or the interplay between state-imposed ideals of spatial order and its contestations, is necessarily a clash (and necessarily in a violent manner, as the abovementioned quote shows) between the state and those citizens who oppose such attempts to regulate space. On this point I would argue that studies of urban informality would be better served by a concept of informality which does not theoretically preclude the empirical possibility of a State trying to inform its spatial policies in a democratic manner, or at least in a way which is deemed acceptable by the affected community. Leaving this possibility open has the great advantage that the (very likely) conflicts arising between a state-sponsored spatial order and social activists may be analysed in terms of discrepant views on concrete implementation of such policies, rather than being "assumed away" as logically necessary.

On the point (iv), a similar reasoning (and a similar departure from Lefebvre's thinking) might be followed. This last point, it will be reminded, regarded the question whether the formalisation of informal practices should be seen as desirable. Lefebvre was very clear that the conflict between the state (Representations of space) and critical strata of society (Spaces of representation) is irreducible. He depicted states as seeking to project order into space, and as doing so by means of violence if necessary. To be clear, I am not seeking to advance here a post-political view that States and other forms of political authority "mean well" or that they only seek to benefit their people. My argument is aimed at the way such issues are analysed and interpreted. A-priori critical perspectives on what State do have the disadvantage of making in-depth analyses of actual policies useless, since the question of whether or not these might be desirable for citizens is already negatively answered. 


\section{References}

[1] H. Lefebvre: The Production of Space. Oxford : Blackwell (1991)

[2] Informal income opportunities and urban employment in Ghana. In: K. Hart: 11, 1973, Journal of modern african studies, Vol. I, pp. 61-89

[3] Deep Democracy: Urban Governmentality and the Horizon of Politics. Appadurai, Arjun. 14, (2002), Public Culture, Vol. I, pp. 21-47

[4] N. AlSayyad: Urban informality as a "new" way of life. In: [ed.] R. Ananya, A. Nezar. Urban Informality. Transnational Perspectives from the Middle East, Latin America and South Asia. Lanham, ML : Lexinbgton Books, (2004), pp. 7-30

[5] H. De Soto: The Other Path: The invisible revolution in the Third World. New York : Harper and Row, (1989)

[6] W. Maloney: Informality Revisited. 32, 2004, World Development, Vol. VII, pp. 1159-1178

[7] J. Perlman: The myth of marginality. Urban poverty and politics in Rio de Janeiro. s.1. : University of California Press, (1979)

[8] O. Yiftachel, H.Yakobi: Control, resistance and informality. In: Urban ethnocracy in Beer-Sheva, Israel. [book auth.] Ananya, AlSayyad, Nezar Roy. Urban Informality. 2003

[9] J. Holston: Insurgent citizenship. Disjunctions of democracy and modernity in Brazil. Princeton : Princeton University Press, (2008)

[10] Rethinking informality. Politics Crisis and the City. McFarlane, Colin. 13, (2012), Vol. I

[11] S. Elden: Understanding Henri Lefebvre. Theory and the Possible. I. New York : Continuum, (2004)

[12] R. Shields: Lefebvre, Love and Struggle. Spatial dialectics. II. London : Routledge (2005)

[13] R. Bromley: Introduction - The Urban Informal Sector: Why Is It Worth Discussing? In: World Development, (1978), Vol. 6, 9/10, pp. 1033-1039

[14] A. Roy, N. AlSayyad: Urban Informality: Transnational Perspectives from the Middle East, Latin America, and South Asia. Lexington Books : s.n., (2004) 